\title{
TRIAGEM SOROLÓGICA DE FAMILIARES DE PACIENTES COM DOENÇA CELÍACA: anticorpos anti-endomísio, antitransglutaminase ou ambos?
}

\author{
Shirley Ramos da Rosa UTIYAMA', Flávia Raphaela NASS'1, Lorete Maria da Silva KOTZE², \\ Renato Mitsunori NISIHARA', Altair Rogério AMBROSIO' ${ }^{1}$ e lara Taborda de MESSIAS-REASON ${ }^{1}$
}

\begin{abstract}
RESUMO - Racional - A doença celíaca representa, na atualidade, a doença intestinal mais comum em populações caucasóides e apresenta prevalência que varia de $8 \%$ a $18 \%$ nos familiares dos pacientes. A pesquisa dos anticorpos anti-endomísio (EmA-IgA) e antitransglutaminase tecidual (anti-tTG-IgA) constitui importante recurso não-invasivo e sensível de triagem e diagnóstico da doença celíaca em grupos de risco e populações. Objetivos - Avaliar a prevalência do EmA e anti-tTG em um grupo de familiares de celíacos e verificar o grau de concordância

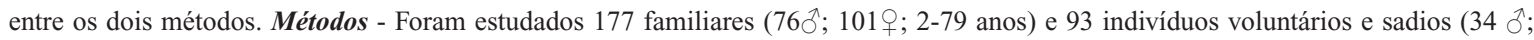
59 ○; 2-71 anos) como grupo controle. O EmA foi detectado por imunofluorescência indireta (substrato: cordão umbilical humano) e o antitTG pelo método de ELISA (kit comercial). Resultados - A positividade total de anticorpos nos familiares em estudo foi de 21\% (37/177), mostrando significativa diferença em relação aos controles $(0 \% ; 0 / 93)$. Doze por cento $(21 / 177)$ dos familiares foram positivos para o EmA e 13,56\% (24/177) para o anti-tTG, sendo 4,52\% (8/177) positivos concomitantemente para os dois anticorpos. A concordância de resultados entre os dois métodos foi de 83,6\% (148/177) e a discordância de 16,4\% (29/177), caracterizando uma correlação positiva significante $(r=0.435)$ entre ambos. Dentre os concordantes, 79,1\% (140/177) eram negativos para o anti-tTG e EmA, e 4,52\% (8/177) positivos para ambos. Nos casos discordantes, 7,34\% (13/177) apresentaram EmA positivo e anti-tTG negativo e 9,04\% (16/177) eram anti-tTG positivo e EmA negativo. Conclusões - Embora a alta positividade obtida para o EmA e anti-tTG destaque a importância da triagem sorológica em familiares de pacientes com doença celíaca, as discordâncias detectadas no estudo permitem ressaltar que o uso isolado de um único método pode incorrer em reações falso-negativas. O impacto desse fato implica que tais familiares deixarão de ser submetidos a biopsia intestinal para confirmação do diagnóstico da doença, e conseqüentemente, ao tratamento adequado e precoce.
\end{abstract}

DESCRITORES - Doença celíaca. Testes sorológicos. Família. Auto-anticorpos. Transglutaminases. Imunoglobulinas.

\section{INTRODUÇÃO}

Os avanços dos últimos anos na compreensão dos aspectos clínicos, epidemiológicos, genéticos e imunológicos da doença celíaca (DC) transformaram-na em um tema de investigação científica de interesse crescente ${ }^{(1,4,6,16,27)}$. Alguns pontos foram fundamentais para que esse avanço acontecesse. O desenvolvimento de testes sorológicos mais sensíveis e específicos, inicialmente com destaque para o anticorpo anti-endomísio (EmA-IgA), foi um marco na história da doença. A introdução de triagens sorológicas trouxe à tona a prevalência elevada da DC nas mais diversas populações e do elevado número de indivíduos assintomáticos. Aliado a esse aspecto, a gradual elucidação da imunopatogênese da doença e o reconhecimento da transglutaminase tecidual como o auto-antígeno que conduz o processo, levou à introdução de um teste semiquantitativo, por ELISA, para pesquisa do anticorpo antitransglutaminase (anti-tTG-IgA), de especificidade similar ao EmA-IgA.

A ampla utilização desses testes e o papel que os mesmos passaram a representar tanto no diagnóstico dos pacientes ${ }^{(12,15,26)}$, como na triagem em grupos de risco, tais como familiares de celíacos, pacientes com diabetes mellitus, com outras doenças auto-imunes ${ }^{(25)}$ e com síndrome de Down ${ }^{(20)}$, entre outros, permitiu que os testes sorológicos na atualidade, aliados aos dados da biopsia intestinal, viessem a compor o padrão-ouro no diagnóstico da DC, de acordo com os critérios de $2005^{(2)}$.

Os inúmeros estudos de triagem da DC evidenciam que os familiares de pacientes, sejam de primeiro ou segundo graus, constituem o grupo de risco com maior

\footnotetext{
'Laboratório de Imunopatologia, Hospital de Clínicas, Universidade Federal do Paraná, ${ }^{2}$ Serviço de Gastroenterologia, Hospital Universitário Cajuru, Pontifícia Universidade Católica do Paraná, Curitiba, PR.

Correspondência: Dra. Shirley Ramos da Rosa Utiyama - Laboratório de Imunopatologia - Departamento de Patologia Médica - Rua Padre Camargo, 280 - $80060-240$
} - Curitiba, PR. E-mail: shirley@ufpr.br 
prevalência da doença ${ }^{(5,6,7,8)}$. Em uma abordagem atual, não cabe apenas se referir ao paciente celíaco, e sim, à família celíaca. $\mathrm{O}$ sul do Brasil, pela característica altamente miscigenada de sua população, com forte ascendência européia, apresenta grande prevalência da $\mathrm{DC}^{(11,19)}$, sendo amplamente pertinentes os estudos com familiares de celíacos dessa população.

As pesquisas com familiares de celíacos são de grande importância na detecção de formas brandas ou latentes da DC, bem como na caracterização de múltiplos casos da doença dentro de uma mesma família ${ }^{(18)}$. Tem-se demonstrado, ainda, diferente prevalência da doença conforme o grau de parentesco ${ }^{(3)}$. Tais aspectos são relevantes não apenas sob o ponto de vista genético, mas principalmente, por permitirem que se detectem pacientes antes que os mesmos desenvolvam sérias complicações. A introdução de dieta isenta de glúten precoce nesses indivíduos previne comprometimentos tardios da DC, como problemas gineco-obstétricos, osteoporose e malignidade ${ }^{(1,9,10,13,14,18)}$.

Considerando-se tais aspectos, o presente estudo teve por objetivo avaliar a prevalência do EmA-IgA e anti-tTG-IgA em um grupo de familiares de pacientes com DC e verificar o grau de concordância entre os dois métodos.

\section{MÉTODOS}

O estudo foi aprovado pelo Comitê de Ética do Hospital de Clínicas da Universidade Federal do Paraná (HC-UFPR), Curitiba, PR e desenvolvido no Laboratório de Imunopatologia desse hospital, com prévio esclarecimento e consentimento dos indivíduos dos grupos em estudo.

\section{Amostras sorológicas}

\section{a) Familiares de celíacos}

Foram estudadas amostras de soros de 177 familiares de pacientes com DC (155 familiares de primeiro grau e 22 de segundo grau), voluntários, pertencentes a 60 famílias. Desses, $57,06 \%$ eram do sexo feminino e $42,94 \%$ do sexo masculino, com idade variando de 2 a 79 anos. A média de familiares investigados foi de 3,18 por família. Por ocasião da coleta de sangue todos responderam a um questionário, no qual declararam fazer uso normal de alimentos contendo glúten.

\section{b) Grupo controle}

Como controle foram estudados 93 indivíduos voluntários e sadios da mesma área geográfica, que apresentavam a maior proximidade possível em relação ao sexo, idade e origem étnica dos familiares, sendo $63,44 \%$ do sexo feminino e $36,56 \%$ do masculino, com idade variando de 2 a 79 anos. Esse grupo foi composto, principalmente, de profissionais da área da saúde do HC-UFPR, entre outros voluntários.

\section{Metodologia}

a) Pesquisa de anticorpos anti-endomísio (EmA-IgA)

A investigação de EmA-IgA nas amostras em estudo foi realizada por técnica de imunofluorescência indireta (IFI), conforme descrito por VOLTA et al. ${ }^{(28)}$. Utilizou-se, como substrato, cortes criostáticos de cordão umbilical humano. As amostras de soro foram diluídas inicialmente a $1 / 2,5$, em tampão fosfato salina (PBS), pH 7,2. Foi utilizado conjugado fluorescente anti-IgA humano (INOVA, San Diego, Ca, USA).

As leituras foram realizadas em microscópio de fluorescência Olympus, sendo consideradas positivas as amostras que caracterizaram fluorescência no tecido de endomísio (substância intermiofibrilar) que contorna as fibras de músculo liso na parede dos vasos e artérias do cordão umbilical. Todos os soros positivos na diluição inicial de triagem foram retestados para definição do título final de EMA-IgA.

b) Pesquisa de anticorpos antitransglutaminase (antitTG-IgA)

A pesquisa foi realizada pelo método de ELISA, conforme descrito por DIETERICH et al. ${ }^{(4)}$, utilizando kit comercial (INOVA, San Diego, Ca, USA). A reação ocorre basicamente com o antígeno purificado de transglutaminase tecidual, de guinea pig, fixado às escavações em placas de poliestireno. Utilizase conjugado de anti-IgA ligado à peroxidase e um substrato cromogênico que leva ao desenvolvimento de cor com intensidade diretamente proporcional à concentração de anticorpos anti-tTG presente nas amostras em análise. A leitura da densidade ótica foi realizada em espectrofotômetro a $450 \mathrm{~nm}$ (Organon Teknika Reader 530, versão 1,24). Amostras com resultados inferiores a 20 unidades foram consideradas negativas, conforme critérios do kit utilizado.

\section{c) Análise estatística}

A análise estatística foi realizada com o software STATISTICA, aplicando-se o teste de Fisher e o método de correlação de Pearson. O nível de significância adotado foi menor que 0,05 $(P<0,05)$.

\section{RESULTADOS}

Os resultados obtidos nas determinações dos anticorpos antiendomísio e antitransglutaminase nos familiares de pacientes com doença celíaca e nos indivíduos do grupo controle podem ser observados na Figura 1. A positividade total de anticorpos detectada nos familiares foi de $21 \%(37 / 177)$ e na população controle de $0 \%(0 / 93)$, caracterizando uma diferença estatística significativa entre os grupos $(P<0.00001)$. Os títulos do EmAIgA apresentaram variação na faixa de diluição de 1:2.5 até 1:80. Em relação ao anti-tTG-IgA, a média dos valores das unidades obtidas entre as amostras de familiares na pesquisa de anticorpos foi de 21,74 unidades, variando de 5 a 195 unidades. Avaliando, separadamente, o grupo de familiares de primeiro grau $(n=155)$ e de segundo grau $(n=22)$, observa-se positividade similar entre ambos, de $21,3 \%$ (33/155) e $18,2 \%$ (4/22), respectivamente.

No total, 12\% (21/177) dos familiares apresentaram o EmAIgA positivo e $13,56 \%$ (24/177) foram anti-tTG-IgA positivos, sendo que $4,52 \%$ (8/177) foram positivos concomitantemente para os dois anticorpos. Nos soros do grupo controle sadio, 
todas as amostras (93/93) apresentaram-se negativas para os anticorpos anti-tTG-IgA e EmA-IgA (Figura 1), caracterizando concordância de $100 \%$ entre os dois métodos.

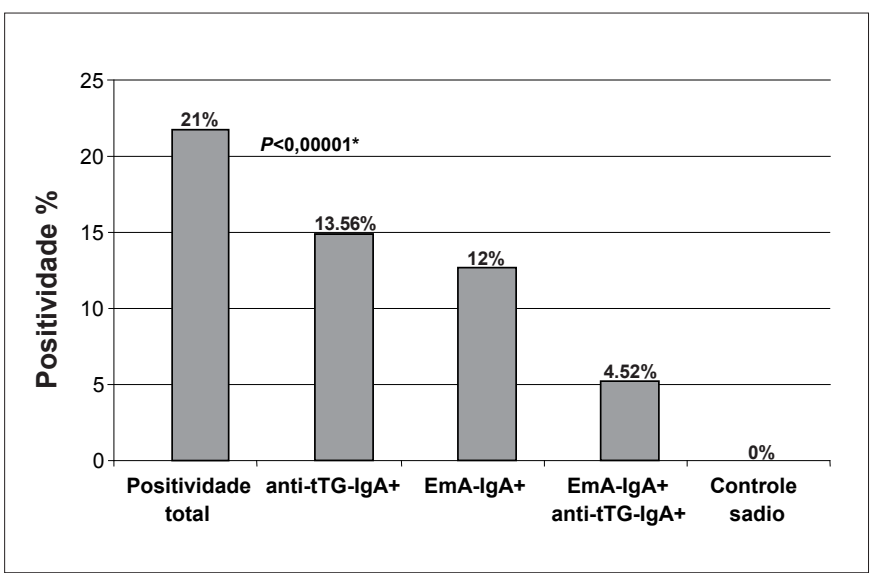

FIGURA 1. Positividade da análise sorológica em familiares de pacientes celíacos

A concordância obtida entre os métodos empregados, em relação aos familiares, foi de 83,62\% (148/177) e a discordância foi de 16,38\% (29/177), como pode ser observado no Figura 2. Dentre os concordantes $(\mathrm{n}=148), 94,6 \%(140 / 148)$ eram negativos para o anti-tTG-IgA e EmA-IgA, enquanto 5,40\% (8/148) eram positivos para ambos (Figura 3). No grupo de casos discordantes $(\mathrm{n}=29), 16$ familiares apresentaram o anti-tTG-IgA positivo e o EmA-IgA negativo $(16 / 29 ; 55,2 \%)$. Por outro lado, 13 foram anti-tTG-IgA negativo e EmA-IgA positivo (13/29; 44,8\%), como se evidencia no Figura 4. Nessas situações, o anti-tTGIgA variou de 25 a 106 unidades, enquanto o EmA-IgA teve a variação de títulos de 1:2.5 a 1:40. A análise de correlação de Pearson caracterizou um coeficiente de relação $r=0.435$ $(P<0,0001)$ entre os métodos empregados (Figura 5).

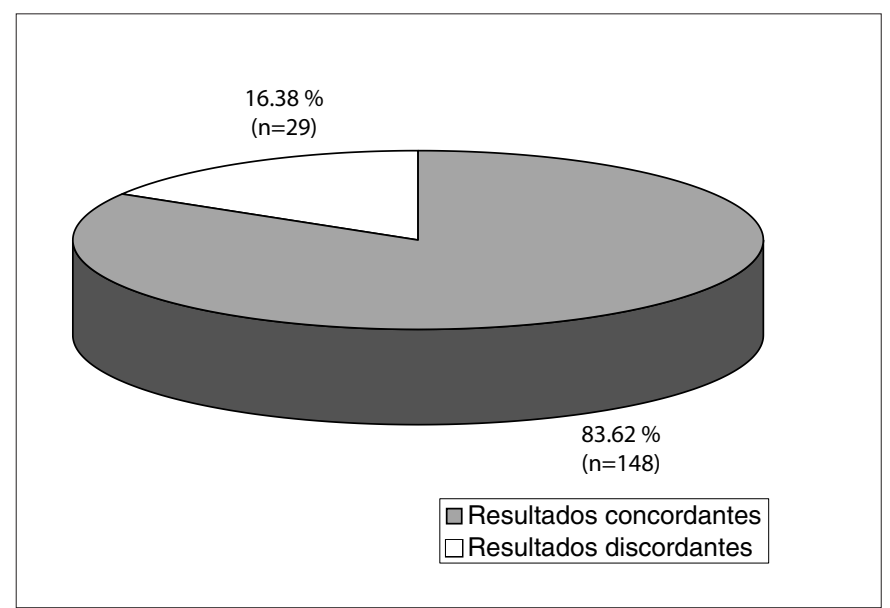

FIGURA 2. Análise sorológica em familiares de pacientes com doença celíaca $(\mathrm{n}=177)$

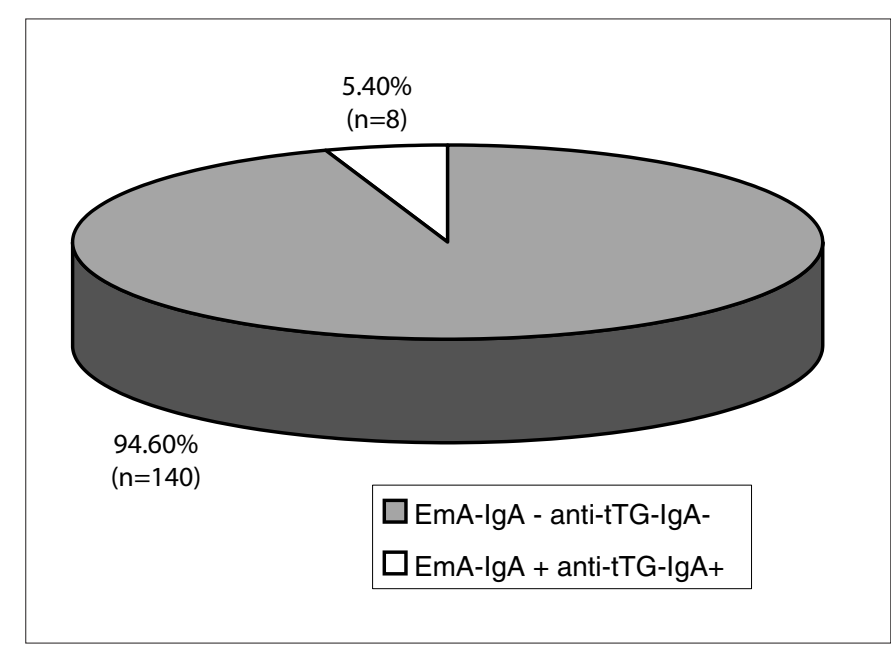

FIGURA 3. Concordância para os anticorpos anti-endomísio e antitransglutaminase em familiares de pacientes celíacos $(n=148)$

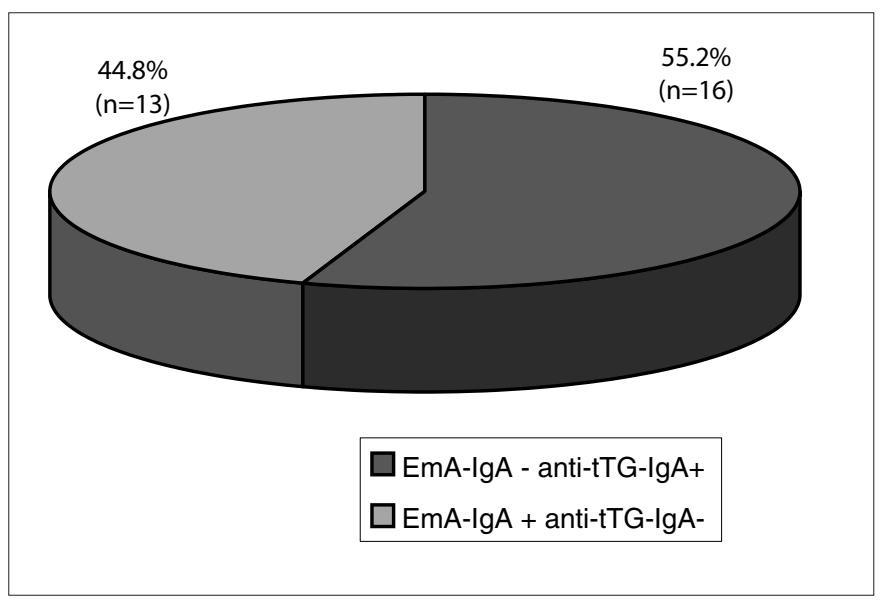

FIGURA 4. Discordância para os anticorpos anti-endomísio e antitransglutaminase em familiares de pacientes celíacos $(n=29)$

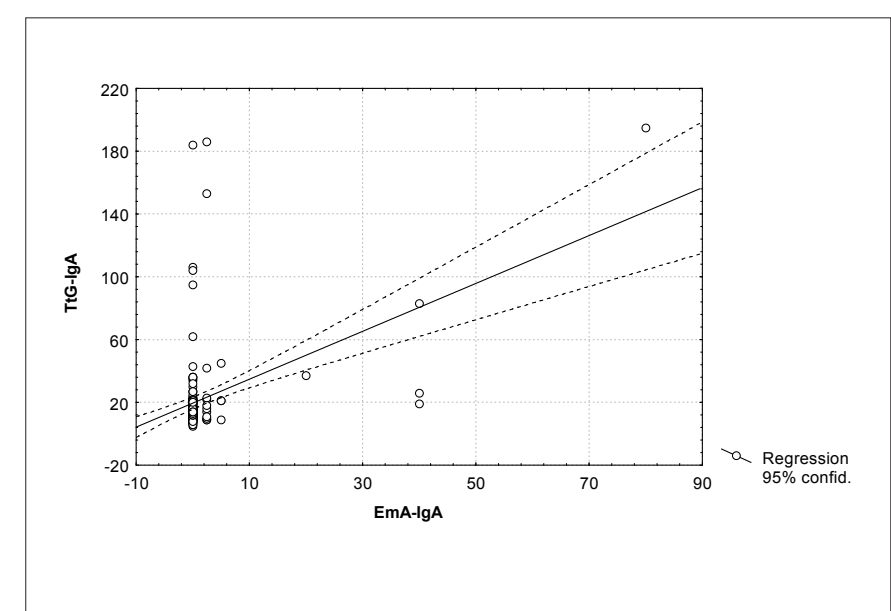

FIGURA 5. Correlação entre os anticorpos EmA-IgA e anti-TTtG-IgA Correlação: $\mathrm{r}=0,435 ; P<0,0001$ 
A Figura 6 ilustra a análise geral dos dados sorológicos obtidos no total de 177 familiares de pacientes com DC. Destacam-se 79,10\% (140/177) dos indivíduos como negativos para os dois métodos em contraste a 4,52\% (08/177) com positividade para ambos. Por outro lado, 9,04\% (16/177) foram positivos apenas para o anti-tTG-IgA e 7,34\% (13/177) apenas para o anticorpo EmA-IgA.

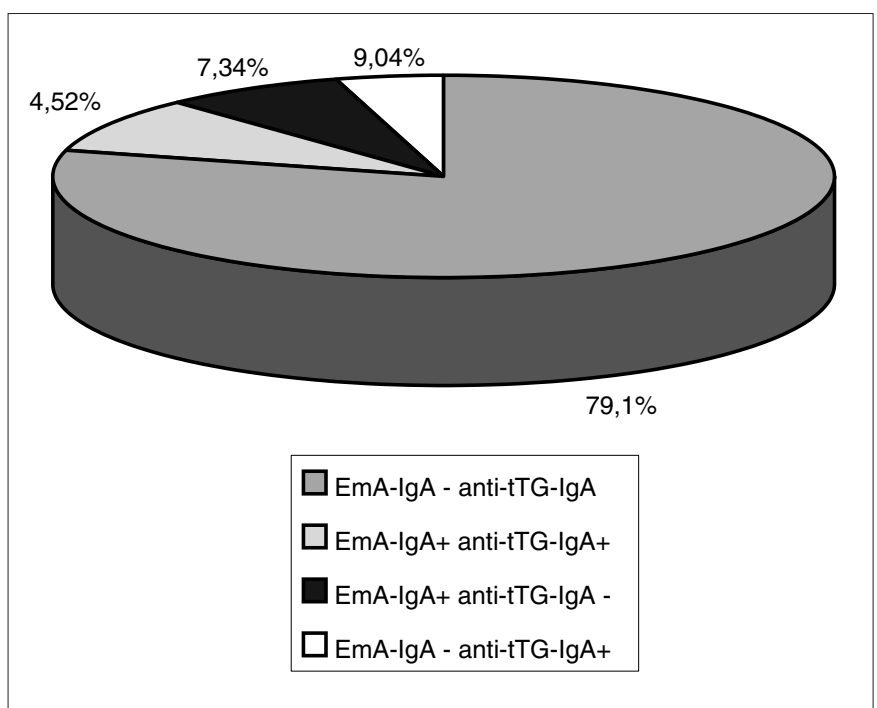

FIGURA 6. Análise geral do estudo sorológico em familiares de celíacos $(\mathrm{n}=177)$

\section{DISCUSSÃO}

Embora seja vasta a literatura de triagem de familiares de pacientes com DC, grande parte dos estudos relata o uso isolado de apenas um método sorológico ou a associação de métodos como o EmA-IgA e o anti-gliadina (AGA), às vezes usando o anti-tTGIgA apenas na confirmação dos casos positivos ${ }^{(3,7)}$. Verifica-se que, embora o EmA-IgA seja amplamente utilizado, dificuldades técnicas no preparo do substrato e as diferenças interobservadores na leitura, aliados aos aspectos de custo, têm gradualmente levado os laboratórios a maior aceitação do uso do anti-tTG-IgA, por ELISA. No entanto, estudos comparativos entre os ensaios são escassos e, em geral, não esclarecem ao clínico qual seria o teste mais adequado. Questionamentos sobre a concordância entre os métodos, aspectos de reações falso-positivas ou falso-negativas, ou os títulos ou concentrações mais detectados nos estudos em familiares, freqüentemente não são relatados. Os dados da presente pesquisa vêm ao encontro de alguns desses aspectos.

Dentre os 177 familiares avaliados, obteve-se positividade total de anticorpos EmA-IgA e anti-tTG-IgA em 37 indivíduos $(21 \%)$. Analisando isoladamente cada um dos anticorpos, $13,56 \%$ (24/177) foram anti-tTG-IgA positivos e 12\% (21/177) dos familiares foram EmA-IgA positivos (Figura 1). Ressalta-se que apenas $4,52 \%(8 / 177)$ desses eram positivos simultaneamente para os dois anticorpos. Embora os dados iniciais estejam de acordo com inúmeros relatos mundiais, nos quais se destaca prevalência da doença na faixa de $8 \%$ a $18 \%$ dos familiares de pacientes com DC, a discordância detectada entre os dois métodos é o aspecto de maior ênfase neste estudo.

Dos 177 familiares avaliados, 148 (83,6\%) apresentaram resultados concordantes: 140 eram negativos para os dois métodos empregados, enquanto 8 eram positivos também para ambos. No entanto, os demais 29 familiares, que constituem 16,4\% do total, foram discordantes nos resultados: $16(9,04 \%)$ mostraram positividade apenas na pesquisa do anti-tTG-IgA e 13 (7,34\%) apenas para o EmA-IgA (Figura 2). Tais dados corroboram o coeficiente de relação $(\mathrm{r}=0,435)$ obtido entre os dois métodos empregados e ressaltam a correlação de alta significância entre os mesmos $(P<0,0001)$ (Figura 5), conforme já demonstrado em estudos prévios com pacientes celíacos ${ }^{(12,26)}$. O emprego de um único método de análise poderia incorrer em risco de reação sorológica falso-negativa em ambos os casos. O uso somente do anti-tTG-IgA na triagem deixaria de detectar positividade em 13 indivíduos. $\mathrm{O}$ uso apenas do EmA-IgA na triagem deixaria de detectar positividade em 16 indivíduos. Em ambas as situações, tais indivíduos deixariam de estar sendo encaminhados à biopsia intestinal para confirmação do diagnóstico de DC.

Embora seja conhecido que familiares próximos eventualmente tendem a evitar o uso de alimentos com glúten, com o objetivo de estimular e apoiar o paciente a adesão à dieta, e que esse fato pode levar a reações sorológicas falso-negativas, no presente estudo exclui-se tal possibilidade, considerando que todos declararam alimentar-se normalmente.

Chama a atenção que dentre os oito casos positivos concordantes, predominaram títulos mais elevados para o EmA-IgA $(\geq 1: 20) \mathrm{e}$ anti-tTG-IgA ( $>35$ unidades) na maioria das amostras. Entretanto, nas amostras discordantes, são nitidamente predominantes os títulos baixos naquelas positivas apenas para o EmA-IgA $(\leq 1: 5)$, assim como nas positivas para o anti-tTG-IgA ( $<35$ unidades). Tais aspectos já foram previamente observados em estudos com pacientes com $\mathrm{DC}^{(12)}$.

Embora alguns trabalhos demonstrem 100\% de concordância para o EmA-IgA e anti-tTG-IgA ${ }^{(17,22)}$, resultados similares aos obtidos no presente estudo $(83,62 \%)$ têm sido observados por outros autores. PALACIOS et al. ${ }^{(21)}$, na Espanha, e SUGAI et al. ${ }^{(24)}$, na Argentina, obtiveram $84 \%$ e $87 \%$ de concordância, respectivamente, ao testarem o EmA-IgA e anti-tTG-IgA, porém utilizaram apenas soros de pacientes em uso de glúten e não fazem referências a ensaios em familiares de celíacos.

DOLINSEK et al ${ }^{(5)}$, na Eslovênia, ressaltam maior prevalência da DC entre os familiares de pacientes celíacos em relação à população geral. Relatam que, aliado à pesquisa sorológica efetiva, a tipagem HLA tem provado ser valioso instrumento diagnóstico. Ao avaliarem os familiares para o EmA-IgA e AGA, o diagnóstico de DC foi confirmado por biopsia apenas naqueles que eram positivos para ambos os testes e que apresentavam o alelo HLA de maior risco para a doença. Todos eram assintomáticos ou apresentavam discretas manifestações gastrointestinais. Dentre os dados discordantes do estudo, destacaram-se 8,5\% (9/106) dos familiares positivos apenas para o AGA e $0,94 \%$ (1/106) apenas para o EmA-IgA. Segundo os autores, a triagem sorológica é recomendada para todos os familiares de primeiro grau de pacientes, 
devendo-se ainda proceder à tipagem HLA para detectar aqueles que tenham um fenótipo consistente com DC. Essa conduta já contribuiria para excluir indivíduos que não necessitariam de procedimentos posteriores para o diagnóstico da doença.

Neste contexto, SJOBERG e CARLSSON ${ }^{(23)}$ ressaltam o papel do EmA-IgA e do anti-tTG-IgA na triagem de familiares e salientam o grande número de reações falso-positivas para o AGA em situações como doença crônica do fígado, diabetes, doenças da tireóide e síndrome de Down, entre outras. Os autores destacam o AGA como o melhor teste de triagem em casos de crianças abaixo de 2 anos de idade.

Embora dos 177 familiares em estudo apenas $12,43 \%(n=22)$ fossem de segundo grau, em relação a 87,57\% $(n=155)$ de primeiro grau, a percentagem de positividade entre ambos foi bastante próxima ( $18,2 \%$ e $22 \%$, respectivamente). Estudos recentes têm dado ênfase à prevalência da DC entre os familiares de segundo grau e ressaltam ainda o maior risco para a doença nas situações em que já existem dois irmãos afetados na família, possivelmente devido ao compartilhamento de genes em comum ${ }^{(7,8)}$. BOOK et al..$^{(3)}$, em estudo com famílias com um par de irmãos afetados, identificaram risco aproximadamente dobrado em relação a relatos prévios. Os autores caracterizaram prevalência de $21,3 \%$ entre irmãos, $14,7 \%$ em filhos de celíacos, $17,2 \%$ nos demais familiares de primeiro grau, $19,5 \%$ nos de segundo grau e $17,8 \%$ no total dos familiares. Embora o presente trabalho não seja somente em famílias com pares de irmãos afetados, as percentagens acima citadas mostram algumas semelhanças ao mesmo, ressaltando o elevado risco entre os familiares. Dentre as amostras positivas $(\mathrm{n}=37)$, detectou-se nesta série 40,54\% (15/37) de positividade para os anticorpos entre pais, $24,32 \%(9 / 37)$ entre irmãos e filhos e $10,81 \%(4 / 37)$ entre os familiares de segundo grau. Desses, especificamente, oito eram mães $(21,62 \%)$, sete pais $(18,92 \%)$, cinco irmãs $(13,52 \%)$, quatro irmãos $(10,81 \%)$, uma filha $(2,70 \%)$, oito filhos $(21,62 \%)$, uma neta $(2,70 \%)$, uma sobrinha $(2,70 \%)$ e dois sobrinhos $(5,40 \%)$.

Chama a atenção no estudo o predomínio de familiares do sexo masculino sorologicamente positivos $(56,76 \%$; $21 / 37)$ em relação ao feminino $(43,24 \% ; 16 / 37)$, porém sem alcançar significância estatística. GUDJONSDOTTIR et al. ${ }^{(8)}$, em estudos com familiares de pacientes celíacos da Suécia e Noruega, tiveram preponderância no diagnóstico de novos casos de DC entre familiares do sexo masculino. Os autores colocam o achado como inesperado e inexplicado e afirmam não poder sequer atribuí-lo à existência de mais doenças auto-imunes silenciosas no sexo masculino do que no feminino.

Finalizando, os resultados obtidos no presente estudo vêm ao encontro dos dados da literatura mundial e deixam evidentes as discordâncias obtidas entre os diferentes métodos sorológicos. Tal fato deve ser ressaltado e divulgado no meio médico, ao se considerar que, na maioria das vezes, é a partir da informação da triagem sorológica que os indivíduos são encaminhados para confirmação do diagnóstico pela biopsia intestinal. Até o momento, dentre os 21 familiares EmA-IgA positivos, 11 que concordaram em se submeter a avaliação histológica, tiveram o diagnóstico da doença confirmado e já fizeram parte de relatos prévios dessa linha de pesquisa ${ }^{(11,27)}$. Aqueles positivos apenas para o anti-tTG-IgA, detectados mais recentemente, estão sendo orientados a realizar a biopsia intestinal e os dados deverão ser relatados oportunamente. Na seqüência ainda, o seguimento dos familiares em estudo utilizando kits com transglutaminase humana trará informações adicionais que deverão respaldar os dados já obtidos.

\section{CONCLUSÃO}

Os dados da presente pesquisa permitem sugerir que o uso isolado de um único método sorológico na triagem de familiares de pacientes com DC pode incorrer em resultados falso-negativos. Como conseqüência, pode-se acarretar prejuízo na conduta seqüencial de orientação desses indivíduos para confirmação do diagnóstico pela biopsia intestinal e na instituição do tratamento adequado e precoce, antes das manifestações da própria DC, doenças associadas e/ou complicações.

Utiyama SRR, Nass FR, Kotze LMS, Nisihara RM, Ambrosio AR, Messias-Reason IT. Serological screening of relatives of celiac disease patients: antiendomysium antibodies, anti-tissue transglutaminase or both? Arq Gastroenterol. 2007;44(2):156-61.

ABSTRACT - Background - Celiac disease is the most common intestinal disorder of caucasian populations and presents a prevalence of $8 \%$ to $18 \%$ between the relatives of patients. The anti-endomysial (IgA-EmA) and anti-tissue transglutaminase antibodies (IgA-tTG) have represented an important non invasive and sensitivity method of screening and diagnosis of celiac disease in risk groups and populations. Aims - To investigate the prevalence of IgA-EmA and IgA-tTG antibodies in relatives of celiac patients and verify the degree of concordance between them. Methods - One hundred and seventy seven relatives of celiac patients $(76 \hat{0} ; 101 \% ; 2-79$ years) and 93 healthy individuals were evaluated $(34 \AA 599 ; 2-71$ years). IgA-EmA were detected by indirect immunofluorescence, with human umbilical cord as substrate, while anti-IgA-tTG titers were measured by enzyme-linked immunosorbent assay (ELISA), using commercial kit. Results - Total positivity to antibodies in relatives of celiac patients was of $21 \%(37 / 177)$, and showed significant difference compared to control group $(0 \%$; 0/93). Twelve percent $(21 / 177)$ of celiac disease relatives were positive to IgA-EmA, $13.56 \%(24 / 177)$ to IgA-tTG, and $4.52 \%(8 / 177)$ to both assays simultaneously. The concordance between both methods was $83.6 \%(148 / 177)$ and the discordance was $16.4 \%(29 / 177)$, with a positive and significant correlation $(\mathrm{r}=0.435)$. Among the concordant results, $79.1 \%(140 / 177)$ were negative and 4.52\% (8/177) were positive to both antibodies. Among the discordant results, $7.34 \%$ (13/177) were positive to IgA-EmA and negative to IgA-tTG, while $9.04 \%$ (16/177) were negative to IgA- EmA and positive to IgA-tTG. Conclusions - Although the high positivity to IgA-EmA and IgA-tTG emphasizes the importance of the serological screening in relatives of celiac patients, the discordances detected in this study showed that the use of only one method can lead to false negative results. Consequently these relatives will not be submitted to intestinal biopsy to confirm the diagnosis of celiac disease, and to the correct and earlier treatment.

HEADINGS - Celiac disease. Serologic tests. Family. Autoantibodies. Transglutaminases. Immunoglobulins. 


\section{REFERÊNCIAS}

1. Askling J, Linet M, Gridley G, Halstensen TS, Ekstrom K, Ekbom A. Cancer incidence in a population-based cohort of individuals hospitalized with celiac disease or dermatitis herpetiformis. Gastroenterology. 2002;123:1428-35.

2. Bai J, Zeballos E, Fried M, Corazza GR, Schuppan D, Farthing MJG, Catassi C, Greco L, Cohen H, Krabshuis JH. Celiac disease. World J Gastroenterol. 2005;10 suppl:1-8.

3. Book L, Zone JJ, Neuhausen SL. Prevalence of celiac disease among relatives of sib pairs with celiac disease in U.S. families. Am J Gastroenterol. 2003;98:377-81.

4. Dieterich W, Ehnis T, Bauer M, Donner P, Volta U, Riecken EO, Schuppan D Identification of the tissue transglutaminase as the auto antigen of celiac disease. Nat Med. 1997;3:797-801

5. Dolinsek J, Urlep D, Karell K, Partanen J, Micetic-Turk D. The prevalence of celiac disease among family members of celiac disease patients. Wien Klin Wochenschr. 2004;116 suppl 2:8-12.

6. Dube C, Rostom A, Sy R, Cranney A, Saloojee N, Garrity C, Sampson M, Zhang L, Yazdi F, Mamaladze V, Pan I, Macneil J, Mack D, Patel D, Moher D. The prevalence of celiac disease in average-risk and at-risk Western European populations: a systematic review. Gastroenterology. 2005;128 (4 suppl 1):s57-s67.

7. Fasano A, Berti I, Gerarduzzi T, Not T, Colletti RB, Drago S, Elitsur Y, Green PH, Guandalini S, Hill ID, Pietzak M, Ventura A, Thorpe M, Kryszak D, Fornaroli F, Wasserman SS, Murray JA, Horwath K. Prevalence of celiac disease in at-risk and not-at-risk groups in the United States: a large multicenter study. Arch Intern Med. 2003; $163: 286-92$

8. Gudjonsdottir AH, Nilsson S, Ek J, Kristiansson B, Ascher H. The risk of celiac disease in 107 families with at least two affected siblings. J Pediatr Gastroenterol Nutr. 2004;38:338-42.

9. Hervonen K, Hakanen M, Kaukinen K, Collin P, Reunala T. First-degree relatives are frequently affected in coeliac disease and dermatitis herpetiformis. Scand J Gastroenterol. 2002;37:51-5.

10. Korponay-Szabo I, Kovacs J, Lorinez M, Torok E, Goracz G. Families with multiple cases of gluten-sensitive enteropathy. Z Gastroenterol. 1998;36:553-8.

11. Kotze LM, Utiyama SR, Nisihara RM, Zeni MP, Sena MG, Amarante HM. Antiendomysium antibodies in Brazilian patients with celiac disease and their first-degree relatives. Arq Gastroentol. 2001;38:94-103.

12. Kotze LM, Utiyama SR, Nisihara RM, de Camargo VF, Ioshii SO. IgA class antiendomysial and anti-tissue transglutaminase antibodies in relation to duodenal mucosa changes in celiac disease. Pathology. 2003;35:56-60.

13. Kotze LM. Gynecologic and obstetric findings related to nutritional status and adherence to a gluten-free diet in Brazilian patients with celiac disease. J Clin Gastroenterol. 2004; 38:567-74

14. Kotze, LM. Doença celíaca. In: Coelho JCU, editor. Aparelho digestivo clínica e cirurgia. $3^{\text {a }}$ ed. São Paulo: Atheneu; 2005. p.703-24.
15. Kotze LM. Doença celíaca e outros distúrbios da absorção dos nutrientes. In: Dani $\mathrm{R}$, editor. Gastroenterologia essencial. $3^{\mathrm{a}}$ ed. Rio de Janeiro: Guanabara Koogan; 2006. p.284-316.

16. Kotze LMS, Nisihara RM, Utiyama SRR, Piovezan GC, Kotze LR. Thyroid disorders in Brazilian patients with celiac disease. J Clin Gastroenterol. 2006;40:33-6.

17. Miller A, Paspaliaris W, Elliott PR, d'Apice A. Antitransglutaminase antibodies and celiac disease. Aust N Z J Med. 1999;29:239-42.

18. Mustalahti K, Lohiniemi S, Collin P, Vuolteenaho N, Laippala P, Maki M. Gluten-free diet and quality of life in patients with screen-detected celiac disease. Eff Clin Pract. 2002;5:105-13

19. Nisihara RM, Utiyama SR, Kotze LM. Prevalência da doença celíaca na região sul do Brasil. In: V Semana Brasileira do Aparelho Digestivo, 2002; Rio de Janeiro, Brasil: Anais da V Semana Brasileira do Aparelho Digestivo; 2002. p.19-20.

20. Nisihara RM, Kotze LM, Utiyama SR, Oliveira NP, Fieldler PT, Messias-Reason IT. Celiac disease in children and adolescents with Down syndrome. J Pediatr (Rio J). 2005;81:373-6.

21. Palacios SM, Rivero MA, Sanchez VVF, Feijoo BE, Ramos AM, Oliveira OJ, Garcia MS. The tissue transglutaminase antibody: usefulness in the diagnosis of celiac disease objective. An Esp Pediatr. 2000;53:542-6.

22. Reeves GE, Burns C, Hall ST, Gleeson M, Lemmert K, Clancy RL. The measureament of IgA and IgG transglutaminase antibodies in celiac disease: a comparison with current diagnostic methods. Pathology. 2000;32:181-5.

23. Sjoberg K, Carlsson A. Screening for celiac disease can be justified in high-risk groups. Lakartidningen. 2004;101:3912, 3915-6, 3918-9.

24. Sugai E, Selvaggio G, Vazquez H, Viola M, Mazure R, Pizarro B, Smecuol E, Flores D, Pedreira S, Maurino E, Gomez JC, Bai JC. Tissue transglutaminase antibodies in celiac disease: assessment of a commercial kit. Am J Gastroenterol. 2000;95:2318-22.

25. Utiyama SR, Kotze LM, Nisihara RM, Carvalho RF, Carvalho EG, Sena MG, Reason IJTM. Spectrum of autoantibodies in celiac patients and relatives. Dig Dis Sci. 2001;46:2624-30

26. Utiyama SRR, Kotze LMS, Nisihara RM, de Camargo VF. Correlação dos anticorpos anti-endomísio e antitransglutaminase com a doença celíaca. Rev Bras Anal Clin. 2002;34:39-45

27. Utiyama SRR, Kotze LMS, Reason ITM. Complement factor B allotypes in the susceptibility and severity of celiac disease in patients and relatives. Int J Immunogenet. 2005;32:307-14.

28. Volta U, Molinaro M, de Franceschi L, Fratangelo D, Bianchi FB. IgA anti-endomysial antibodies on human umbilical cord tissue for celiac disease screening. Save both money and monkeys. Dig Dis Sci. 1995;40:1902-5. 